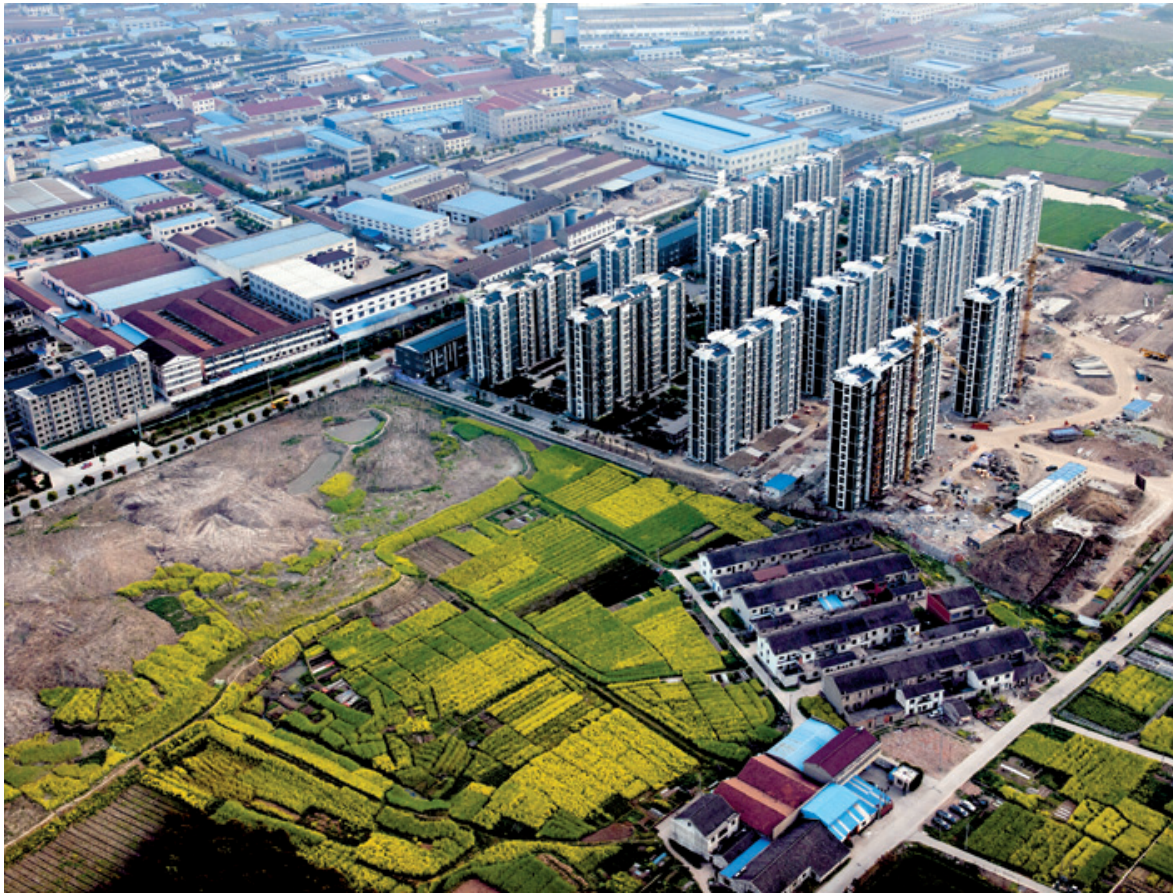

Development in the city of Jiangyin, which lies close to the Yangtze River near China's east coast.

\title{
Realizing China's urban dream
}

\section{Local implementation and public scrutiny will make or break the government's urbanization strategy, say Xuemei Bai, Peijun Shi and Yansui Liu.}

$\mathrm{C}$ hina is urbanizing at an unprecedented rate. It is perhaps the greatest human-resettlement experiment in history. Between 1978 and 2012, the fraction of the nation's population dwelling in cities increased from $17.9 \%$ to $52.6 \%$ (see 'Urban expansion'). If the current trend holds, China's urban population could top 1 billion people in the next two decades.

These are uncharted waters, but China has a plan. In March, the government released the National New-type Urbanization Plan, which sets targets for China's urban population fraction to rise by $1 \%$ a year to reach $60 \%$ by 2020 .

The plan is comprehensive and ambitious. It covers almost every conceivable aspect of urbanization, from rural-urban migration and integration to the spatial distribution of and linkages between cities; sustainable development; institutional arrangements; and implementation. It sets numerical goals (see 'Government targets') and as a guiding principle emphasizes a sustainable and people-centred approach, paying more attention to welfare and well-being - a significant and positive shift from the current economic focus on land development. It also aims to rectify existing problems associated with the rapid urbanization in the past three decades.

The right national strategy is necessary. But it is not sufficient. It is local practices that will make or break China's urbanization plan.

\section{GOVERNMENT GOALS}

President Xi Jinping and Premier Li Keqiang see sustainable urbanization as a policy priority for three reasons.

First, urbanization and industrialization are the two engines of modernization and economic growth. High-income countries typically have high urban population proportions - 70-90\% for countries in the Organisation for Economic Co-operation and Development. By comparison, China's urbanization lags behind its industrialization. Research shows that urbanization does promote economic growth in China ${ }^{1}$, even though the causal link between the two has been questioned ${ }^{2}$.

Second, to keep its economy growing, China needs to shift from its current reliance on exports by spurring domestic demand. Urbanization enhances domestic consumption: per capita income in China is more than three times higher in urban than in rural communities.

Third, urbanization can catalyse regional development. With less than 0.1 hectares of arable land per farmer, rural China has little room to boost income growth by expanding agriculture. Urbanization will reduce the poor agricultural population and the number of smallholder farms, and open up possibilities for accelerated rural development through large-scale, modernized farming practices.

Development is at the core of these rationales, and the government aims to do it in a sustainable way. Building and operating growing cities requires materials and energy, but the demand for some of these will exceed the country's supply capacity ${ }^{3}$. And daunting environmental and social challenges caused by past urbanization need to be avoided.

China aims to guide the development of urban areas according to their resource and environmental carrying capacity; improve land, water and other resource use efficiency; stabilize the employment of migrating workers; and promote green and low-carbon urban construction and operation. Its 12th Five-Year Plan for 2011-15 also aims to reduce construction land use per unit of gross domestic product (GDP) by $30 \%$, energy intensity by $16 \%$ and carbon dioxide emission intensity by $17 \%$.

There is, of course, a catch: if the income of new urban residents matches that of existing ones, the consumption that will fuel China's economic growth will present sustainability challenges to the country and other parts of the world. For example, the rise in $\mathrm{CO}_{2}$ emissions that would result if China's household consumption patterns converge with current US levels could not be offset by efficiency gains alone ${ }^{4}$. Promoting low-carbon lifestyles is mentioned in the plan only in passing and without concrete measures or targets for how they might be achieved.

\section{POLICY CHALLENGES}

To live the urban dream, China faces three policy challenges: land, people and the environment.

In the past decade, the urban built-up land area in China has grown by $78.5 \%$ - faster than its urban population, which grew by $46 \%$. The rapid pace of landscape urbanization is driven by Chinese cities' overreliance on income from land release ${ }^{1}$, which can amount to $70 \%$ of their total revenue. 
Land-release income increased by a factor I of six between 2005 and 2011.

About half of urban growth has been at the expense of arable land, raising concerns about food security. To curb the loss of agricultural $\vdots$ land, the central government has introduced s strict regulations, mandating that cities offset developed land by securing the same amount of arable land elsewhere or reducing the area of land used for rural housing.

These policies have had limited success, and in some cases, adverse consequences. In a desperate search for non-agricultural land

to develop, cities have reclaimed wetlands and lakes and converted pristine mountains. At the same time, developed land is not being used efficiently - attention quickly shifts to the next development project.

The flow of people from rural communities to cities raises problems. Migrating peasant workers, currently estimated at 250 million, are prevented from integrating into urban communities by the household registration system. This restricts the official changing of citizens' permanent residence, and effectively limits those with rural registration from gaining access to urban medical insurance and other services. Migrants typically live in 'urban villages', often former villages or new shanty towns on the edge of a settlement, without adequate social security, health care or schools ${ }^{5}$.

Although forbidden, 'forced urbanization' is widespread. Rural residential lands are being expropriated with insufficient compensation and inhabitants forced into newly developed apartment buildings. Peri-urban communities - those that straddle urban and rural areas - that are affected by expansion often become more vulnerable both socially and economically, with a sudden loss of traditional livelihoods such as farming and fishing, and without adequate skills and access to other jobs.

Neglecting migrants' needs has enabled Chinese cities to grow at low cost. Now this strategy is backfiring. For example, the lack of security and sense of belonging of incoming workers in cities makes them reluctant to give up their rural land quota, which is left uncultivated. They invest their savings to build bigger houses back in the villages, often on agricultural land. Urban crimes and protests for appropriate pay by migrant workers are rising.

Although rural populations are smaller than urban ones, and falling, rural residential land use has increased rapidly. Four times more rural land than urban is being used for construction of all sorts, often inefficiently. More than 7.58 million hectares of potential arable land could be realized by optimizing rural residential land use clearing up discarded residential plots ${ }^{6}$, for example. Integrating migrating workers into

\section{URBAN EXPANSION}

The proportion of China's population living in cities has risen steadily since the 1970s (1). Workers moving from rural areas to cities are prevented from integrating, however, by a household registration system that restricts them from officially changing their permanent residence. Urban populations concentrate in the eastern part of the mainland (2)

1

Relocation trends

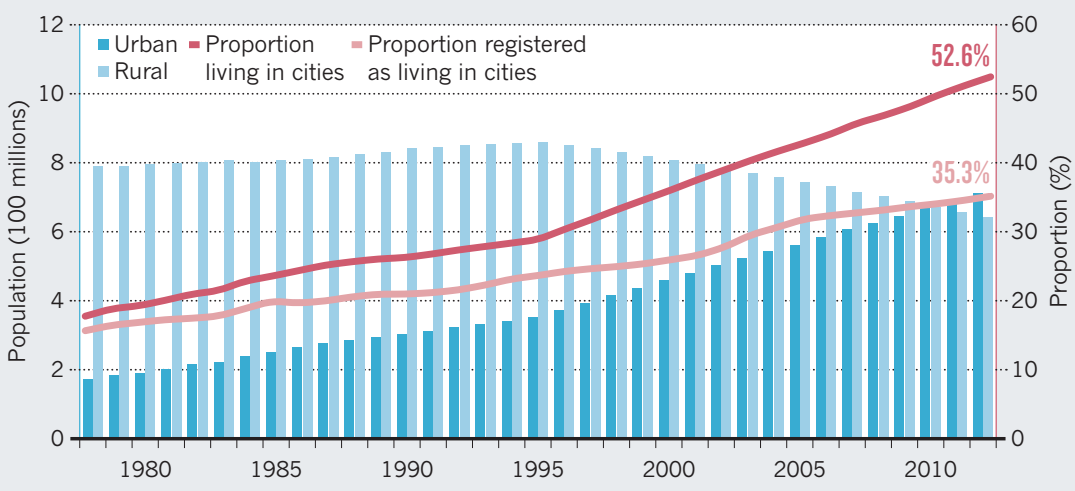

2 Mainland cities

Population density in 2010

(people per $\mathrm{km}^{2}$ )

Below 10

10-50

50-100

$100-500$

500-1,000

- Above 1,000

Urban population

Below 200,000

- 200,000-500,000

-500,000-1 million

- 1 million-2 million

- 2 million-5 million

- Above 5 million

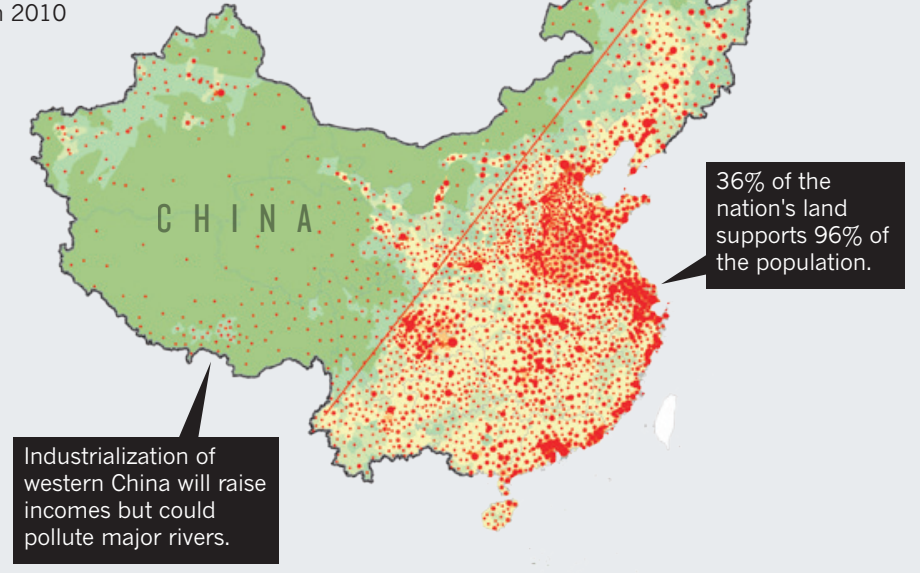

urban life - for instance, by guaranteeing access to education and providing water and sanitation - has costs, but is essential to achieving the state's policy goals and maintaining social stability.

Urbanization is also linked to environmental and health problems ${ }^{7}$. About twothirds of Chinese cities are short of water, exacerbated by severe surface and ground water pollution. Air and water quality in cities and the surrounding rural areas are deteriorating, with increases in respiratory diseases and cancer rates ${ }^{8}$. In 2013, Beijing hit a high for the number of days with smog pollution -46 of the first 100 days of the year. Illegal discharge of industrial wastewater, which contains heavy metals and other pollutants, around cities is blamed by some for more than 400 'cancer villages', in which cancer diagnoses and deaths are sometimes 20-30 times higher than the national average ${ }^{9}$.

Most city development has been in the eastern part of the country, particularly along the coast. The procession of urban and industrial development inland and westwards, to spread manufacturing across the country and reduce regional disparities, is clearly articulated in the government's strategy. But this could bring polluting industries into regions where fragile ecosystems are providing crucial services to the nation. Pollution in western China, for example, which is home to the sources of the Yangtze, Yellow and Lancang rivers, could have profound effects downstream.

Environmental management strategies that stop at cities' administrative boundaries are no longer effective, as epitomized by the frequent regional smogs. Officials need to identify good ways to collaborate across city and regional boundaries.

\section{LOCAL IMPLEMENTATION}

The National New-type Urbanization Plan aims to tackle some of these challenges. The household registration constraints will be removed or relaxed in towns and 


\section{GOVERNMENT TARGETS}

Main indicators and numerical targets in China's National New-type Urbanization Plan.

\begin{tabular}{|c|c|c|}
\hline Indicator & 2012 & 2020 \\
\hline \multicolumn{3}{|l|}{ Urbanization level } \\
\hline Urbanization ratio (resident population) (\%) & 52.6 & 60 \\
\hline \multicolumn{3}{|l|}{ Public services } \\
\hline $\begin{array}{l}\text { Proportion of peasant worker's children accompanying parents receiving } \\
\text { mandatory education (\%) }\end{array}$ & & $\geq 99$ \\
\hline Basic social-security coverage for urban and township resident population $(\%)^{*}$ & 66.9 & $\geq 90$ \\
\hline Basic medical insurance coverage for urban and township resident population (\%) & 95 & 98 \\
\hline \multicolumn{3}{|l|}{ Infrastructure } \\
\hline $\begin{array}{l}\text { Public transportation share in total motorized travel in cities with more than } \\
1 \text { million people (\%) }\end{array}$ & $45+$ & 60 \\
\hline Public water supply coverage in cities and towns (\%) & 81.7 & 90 \\
\hline Proportion of wastewater treated in cities (\%) & 87.3 & 95 \\
\hline Proportion of municipal waste decontaminated in cities (\%) & 84.8 & 95 \\
\hline $\begin{array}{l}\text { Broadband Internet connection capacity of urban households } \\
\text { (megabits per second) }\end{array}$ & 4 & $\geq 50$ \\
\hline \multicolumn{3}{|l|}{ Resource and environment } \\
\hline Per capita urban land use (square metres) & & $\leq 100$ \\
\hline Share of renewable energy consumption in cities and towns (\%) & 8.7 & 13 \\
\hline Share of 'green' buildings in new constructions in cities and towns (\%) & 2 & 50 \\
\hline $\begin{array}{l}\text { Share of prefecture and above level cities that meet the national air-quality } \\
\text { meeting standards (\%) }\end{array}$ & 40.9 & 60 \\
\hline
\end{tabular}

*Excludes resident students and people aged 0-16 years. †Data from 2011. $¥$ Standard is $65-115$ square metres for urban built-up area, and 85-105 square metres in newly developed cities. Translated from the National New-type Urbanization Plan (2014-2020).

cities with populations of up to 5 million. Large investments are to be made to eradicate shanty towns and to provide basic infrastructure in the 'urban villages'.

A new land-management system will increase farmers' property rights, preventing undervalued or illegal land expropriation by local governments. It will restrict rural households from occupying more than one residential plot, putting a stop to ruralsprawl encroaching on arable land. Local governments will be rewarded with central funds for integrating rural populations into the urban system.

The devil, however, is in the detail. Some of these central government reforms conflict with local interests, inviting malpractice. Increased duties of care for migrants and restricted access to land for development will increase the burden on cities and reduce their net revenue.

There are many examples of cities behaving opportunistically. The city of Wuhan, for example, once known for its numerous lakes, has lost $70 \%$ of them to reclamation and development in the past 20 years. The Huai River Pollution Control Project, a high-profile, target-driven initiative led by the central government during the 1990s to clean up the heavily polluted river basin, failed when it collided with local income needs. The main measures - shutting down polluting industries and imposing stronger regulations on

industrial pollutions - were relaxed after the target time frame.

To put people at the centre of policies, leaders need to move away from numerical indicators such as GDP growth or urbanization level, which are often pursued at any expense. City leaders need to be encouraged and rewarded for adopting more responsible and sustainable practices, such as taking care of migrating workers.

Local officials must be made more accountable to deter malpractice. Better methods for evaluating personnel and channels for public scrutiny of officials' actions, perhaps on the Internet, need to be established. Serious breaches of regu-

"Local
officials must
be made more
accountable
to deter
malpractice."

lations must be punishable by law, instead of reprimanded with mere warnings and demotions in the party and the government system.

Some cities are already doing well, exceeding the government's expectations. The city of Zhuhai, for example, has been spearheading the introduction of regulations and legal procedures for making and implementing urban-development plans, promoting public participation urban-development goals with its social, economic, resource and environmental in the planning process and aligning context. Zhuhai topped the sustainabledevelopment ranking in the 2013 Urban Sustainability Index of Chinese cities.

\section{WAY FORWARD}

Governments must not shirk the responsibilities of protecting farmer's rights; providing proper social security and basic urban infrastructure; and ensuring better environmental quality and health outcomes in cities and surrounding regions. They must address risks and hazards such as flooding and smog.

Rapid urbanization is an enormous opportunity to introduce sustainable technologies and practices on a national scale. The latest plan, for example, aims to drastically improve the share of green buildings in new construction from $2 \%$ in 2012 to $50 \%$ by 2020 , by improving green building codes and certificate and accreditation systems, making their adoption compulsory, and developing green construction materials. Efforts must be made to identify innovative practices, build up transferable knowledge and facilitate cross-city learning ${ }^{10}$.

High-level policy intervention, if done properly, can be a powerful force for good. But to succeed, a tailored and adaptive policy approach that engages with local social, environmental, economic and cultural contexts and allows local innovation will be crucial.

The ultimate driver of urbanization is and should continue to be - the aspiration of rural people to lead a better life. And that will be the ultimate measure of success. Urban residents, current and future, must have a say in shaping their cities. They are the ones who will give the verdict on, and live with, the outcome of China's urbanization policy.

Xuemei Bai is professor of urban environment and human ecology at the Australian National University, Canberra, Australia. Peijun Shi is professor at the State Key Laboratory of Earth Surface Processes and Resources Ecology, Beijing Normal University, Beijing, China. Yansui Liu is professor at the College of Resources Science and Technology, Beijing Normal University, Beijing, China.

e-mail:xuemei.bai@anu.edu.au

1. Bai, X., Chen, J. \& Shi, P. Environ. Sci. Technol. 46 132-139 (2012).

2. Bloom, D. E., Canning, D. \& Fink, G. Science 319, 772-775 (2008).

3. Shen, L., Cheng, S., Gunson, A. J. \& Wan, H. Cities 22, 287-302 (2005).

4. Guan, D., Hubacek, K., Weber, C. L., Peters, G. P. \& Reiner, D. M. Glob. Environ. Change 18, 626-634 (2008).

5. Liu, Y., Lu, S. \& Chen, Y. .J. Rural Stud. 32, 320-330 (2013).

6. Liu, Y., Yang, R. \& Li, Y. J. Geograph. Sci. 23, 503-512 (2013).

7. Grimm, N. B. et al. Science 319, 756-760 (2008)

8. Chen, Z., Wang, J.-N., Ma, G.-X. \& Zhang, Y.-S. Lancet 382, 1959-1960 (2013).

9. Liu, L. Environment 52, 8-21 (2010).

10.Bai, X., Roberts, B. \& Chen, J. Environ. Sci. Policy 13, 312-325 (2010). 